
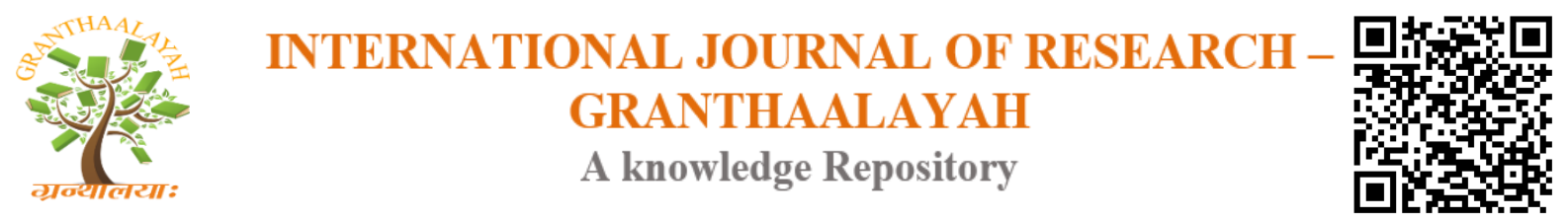

Science

\title{
THE IMPACT OF AGRICULTURAL PRACTICES ON GROUNDWATER QUALITY: A CRITICAL STUDY BASED ON NAVITHANVELI DS DIVISION IN AMPARA DISTRICT IN SRI LANKA
}

\author{
Nijamir.K ${ }^{* 1}$, Kaleel.MIM ${ }^{2}$ \\ ${ }^{* 1,2}$ Department of Geography, South Eastern University of Sri Lanka
}

\begin{abstract}
This study was proceeded to identify the groundwater contamination based on the primary and secondary objectives. The primary objective is "identifying the groundwater contamination by the utilization of agro-chemicals, and the secondary objectives are "finding out Nitrate and Phosphate concentration to identify the Groundwater quality depletion by the chemical testing, identifying adverse agricultural practices and to make awareness among agro-chemical users by inducing traditional agricultural practices and recommend favorable solutions to the groundwater oriented problems in study area. For this study five parameters such as NO3, PO4, EC, pH and Turbidity were analyzed. All the parameters varied from wet season to dry season. Particularly, NO3 and PO4 concentration has deviated from both seasons. The conclusion of the study is that the application of the agrochemicals has impacted on the groundwater quality drastically.
\end{abstract}

Keywords: Contamination; Agricultural Practice; Agro-Chemical; Groundwater.

Cite This Article: Nijamir.K, and Kaleel.MIM. (2017). "THE IMPACT OF AGRICULTURAL PRACTICES ON GROUNDWATER QUALITY: A CRITICAL STUDY BASED ON NAVITHANVELI DS DIVISION IN AMPARA DISTRICT IN SRI LANKA." International Journal of Research - Granthaalayah, 5(9), 36-43. 10.29121/granthaalayah.v5.i9.2017.2195.

\section{Introduction}

Agriculture is one of the major economic sectors and the backbone of the world. Food, being indispensable thing for human existence is the outcome of the agriculture which covers the world by luxuriant crops. According to the report of Food and Agriculture Organization of the United Nations, globally the harvested area 2,781 million hectare. Global employment in agriculture accounts for $30.7 \%$. Approximately, $70 \%$ of total freshwater withdrawal is in the world for the agriculture (FAO, 2015).

At present, enormous amount of agro-chemicals are applied for the agriculture, expecting the high yield. Weed and pest control by weedicides and pesticides and enrichment during the crop growing period, myriad amount of chemical constituents mix with soil and they leach out to the groundwater. Sri Lanka, being an island having 21.4 million population is a lush agricultural 
country. Approximately, $70 \%$ of land supports to the agricultural sector. It is the cornerstone in Sri Lanka's economy with more than $70 \%$ of the population, living in rural areas, depending on agriculture for their livelihood. Currently, this sector contributes to about $18 \%$ of the Gross Domestic Product (GDP) (Trade Chakra, 2010). National employment in agriculture is $39.4 \%$ (FAO, 2015). In recent decades the production has been increased as a result of modernization and using modern techniques utilization of agro-chemical. Acceleration of Mahawali project and its reservoirs help to promote irrigation systems. Other than rice, various other crops such as yams, pulses, grams, vegetables and fruits are produced for consumption (Mother Sri Lanka.info, 2012). For the Agricultural practices, Sri Lanka annually imports approximately 8,000 metric tons (MT) of Agro-chemicals and 900,000 MT of chemical fertilizer (News.1k, 2015). And the application is Nitrogen 130.9 ( $\mathrm{kg}$ of nutrients per ha) and Phosphate 50 ( $\mathrm{kg}$ of nutrients per ha) (FAO, 2015).

Although Sri Lanka has become self-sufficient in rice and some other crops, the adverse effects of chemical usage such as damage to bio-diversity, contamination of water and soil due to chemical substances leading to various health problems, particularly renal diseases in agricultural areas such as North Central and Eastern Provinces. After the green revolution and the advent of the technological advancement, people are globally and nationally using the agro-chemicals such as fertilizers, pesticides and herbicides for the nutrition of crop and weed and pest control during the agricultural practices. These activities lead to the environmental issues. One of the major issues is the contamination of groundwater which is the vital need of the people both drinking and domestic purposes. In Sri Lanka, Ampara District plays an important role in the Paddy production and majority of the peoples cultivate paddy and rely on paddy cultivation for their livelihood. In addition to that, the paddy cultivation, sugar cane, vegetables, chilies and other crops are fairly cultivated in Ampara District. The contribution to the national paddy production from Ampara District is 11\% (Department of Census and Statistics, 2014/2015).

According to the survey, in Ampara District chemical fertilizers have been applied about $64 \%$. The use of both chemical and organic fertilizers were $35 \%$ of the sown extent. Insecticides had been applied in about $72 \%$ of the total sown extent and weedicides had been applied about $84 \%$. Corresponding percentage for 'Hand weeding' was $13 \%$ (Department of Census and Statistics, 2014/2015). In Ampara District, Navithanveli DS Division is renowned for agricultural practices mainly for the paddy cultivation. The inhabitants of this area rely on the paddy cultivation for their livelihood. Besides the paddy cultivation, Maize, Kaupy, Green gram, Ground nut, Cassava, Kurakkan, Black gram and Gingili, are cultivated. And there is no any major feedlots in Navithanveli DS Division. Some people bring slightly up Cow, Goats, and Hens for their own needs. Topography, Geologic condition, Soil types and Structure, Climatic conditions and Vegetation determine the groundwater in any area. Navithanveli DS Division is an arid area, having non-calcic soil. Considering the water resources in Navithanveli DS Division, there is no any major tank but there are some irrigation canals for the paddy cultivation as surface water. People are depending totally on the groundwater mainly for drinking purposes and domestic purposes. In the arid season, some less percolating wells' area people suffering from drought. During that time, the Pradesiya Sabha supply 3 the water with bowser in the affected area. During the rainy season they use rain water which is stored in some storable tanks for the domestic purposes and groundwater recharge. 
The groundwater in Navithanveli DS Division is extracted by manually and electrical pumps for the usages. Further, the pipe-borne water supply is now under construction. It will take time to be accomplished. The excessive utilization of the agrochemicals leads to the groundwater contamination. In Navithanveli DS Division agro-chemicals are applied for controlling pest and weeds as well as to enrich the crops. They are applied indiscriminate manner expecting the high yield without considering the environmental problems. After the utilization, the vacate containers of agro-chemical are disposed improper way. Some farmers dispose the containers to the small streams which carry out the water to the residential area and some washes the instruments used for the agro-chemicals' application. Water from paddy land is discharged through the canals, in doing so, downstream areas and wells nearby the agricultural land areas are subjected to chemical leaching. Consequently, the agro-chemicals leach out to the groundwater aquifers. Once the groundwater aquifers in the hard rock are contaminated, it is difficult to find out and take remedial measures. The Nitrogen and Phosphate rich agro-chemicals are applied in the agricultural practices in Navithanveli DS Division. Therefore, this study purposes to identify the adverse effects of the agro-chemical utilization, depletion of groundwater, the indiscriminate usage of agro-chemicals, improper disposal of vacate containers and to suggest the remedial solutions how to improve the agricultural sector in Navithanveli DS Division effective and efficient one without affecting the environment primarily considering the concentration of agrochemicals on the groundwater.

\section{Materials and Method}

In this study both primary and secondary data have been used. This research has been done by giving prime importance to the primary data in purpose of identifying the exact situation of this study area's problems.

As primary data, 25 wells have randomly been selected for sampling. Of which, 10 wells much closed to the paddy land and 15 wells fairly far from the paddy land. All sampling wells have been numbered to easily identify the water quality analysis in wet and dry seasons. When collecting water from the sampling wells, the depth of the wells and water existing level have been measured. The GPS technology has been manipulated to pinpoint the exact location of sampling wells (25). The results have been analyzed based on the result of water quality analysis report. And also, the direct observation conducted in the agricultural areas and water bodies to observe the application of the agro-chemicals and agro-chemicals' waste disposal. 25 inhabitants as purposive samples were selected to the face to face interview. Besides these, group discussion with Agrarian Service Center, Water Resource Board officials including Chemists and other experts have been interviewed in this regard.

As secondary data, Ampara District Secretariat performance report, Report from Navithanveli DS Division., Performance report Ministry of Agriculture, Statistical report of United Nations' Food and Agriculture Organization, Water Resource Board report, Department of Census and Statistics report and United Nations' Human Settlement report.

Google Earth pro Software has been used to get clear images. Arc GIS10.1 software has been used to the map working. For the result analysis MS Excel, SPSS, and Arc GIS 10.1 applications have been manipulated. 


\section{Results and Discussion}

For the analysis, both wet and dry seasons water quality analysis report were analyzed to identify the variation.

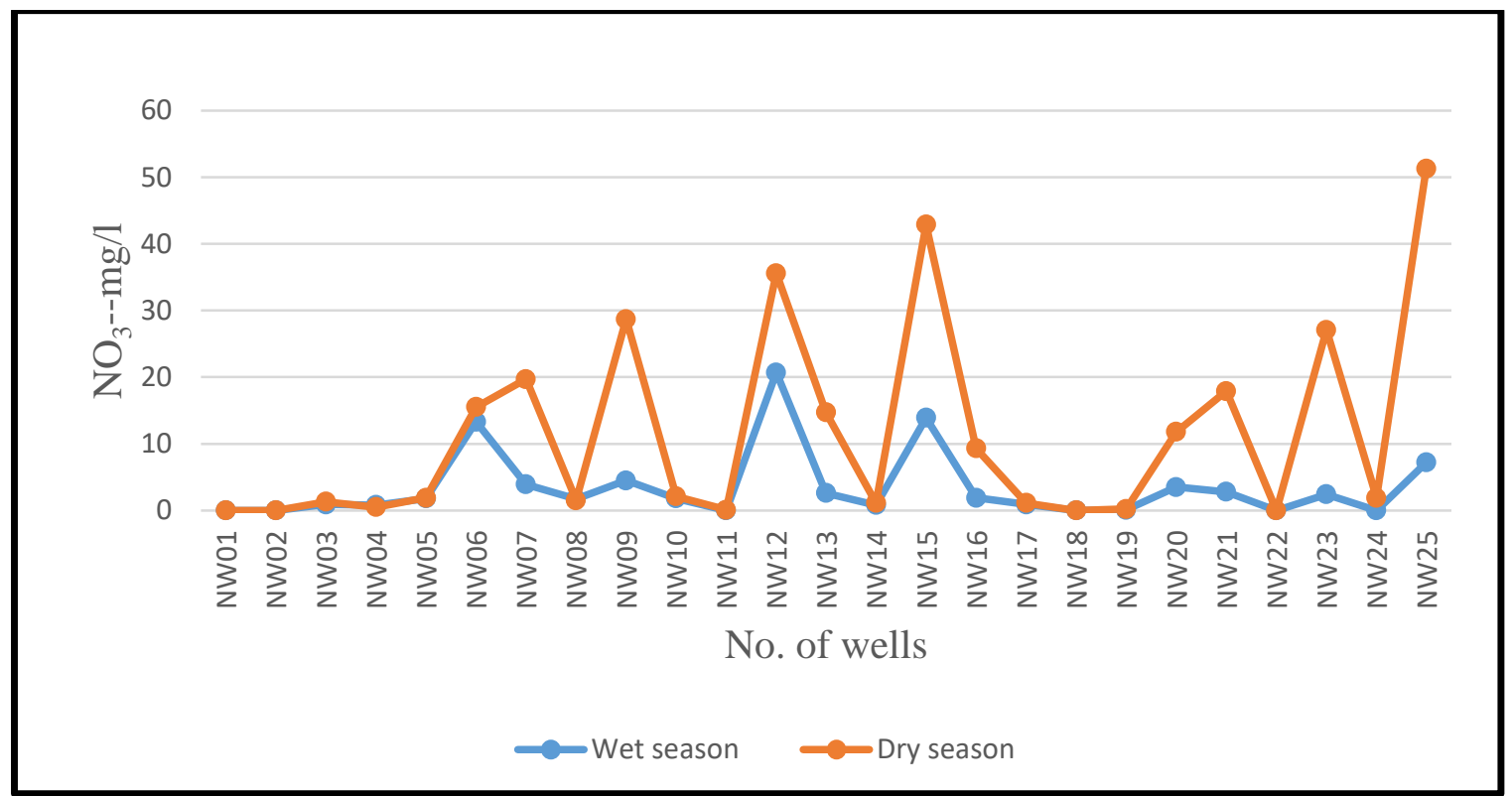

Figure 1: Nitrate variation of wet and dry seasons

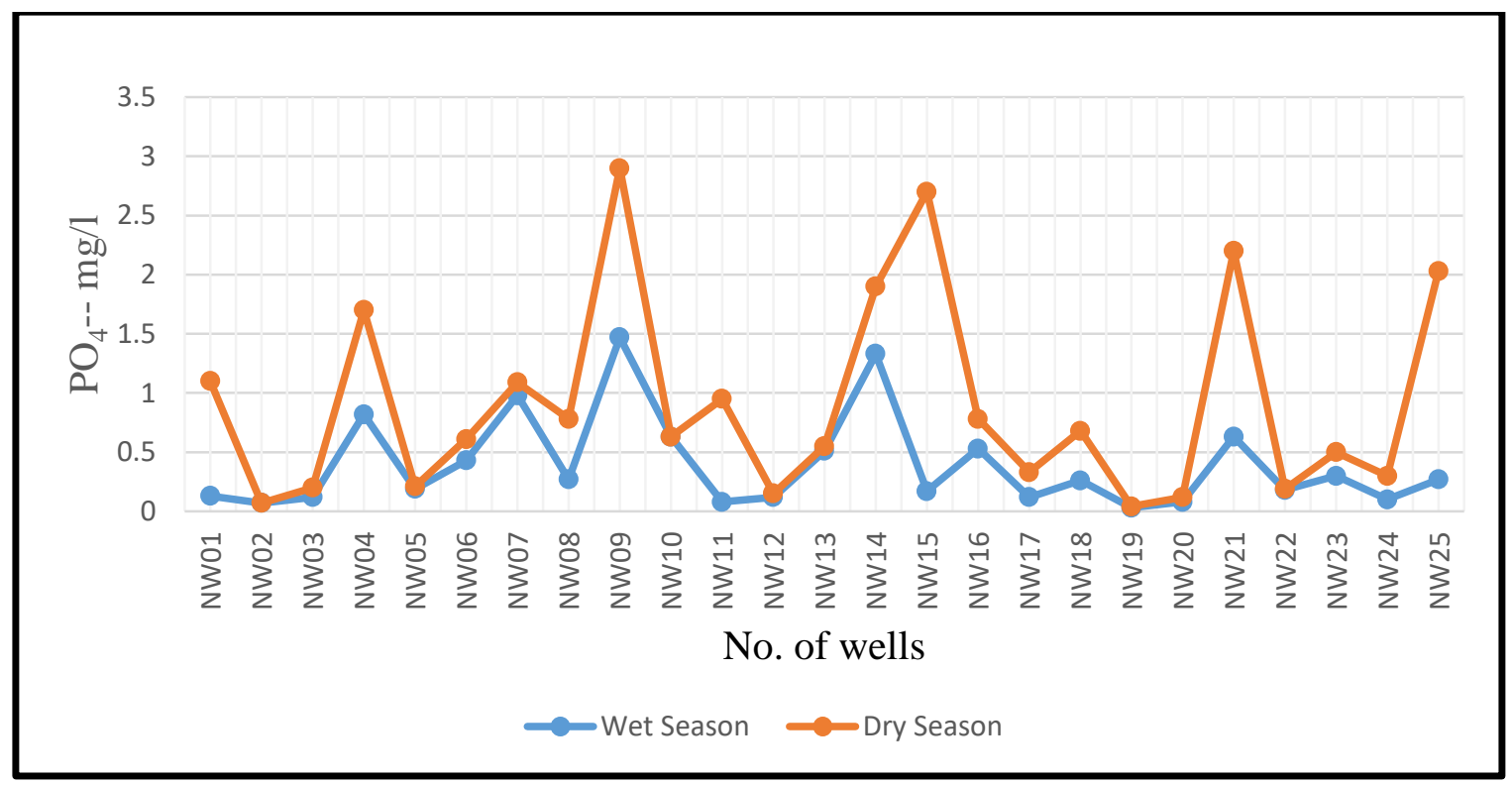

Figure 2: Phosphate variation of wet and dry seasons 


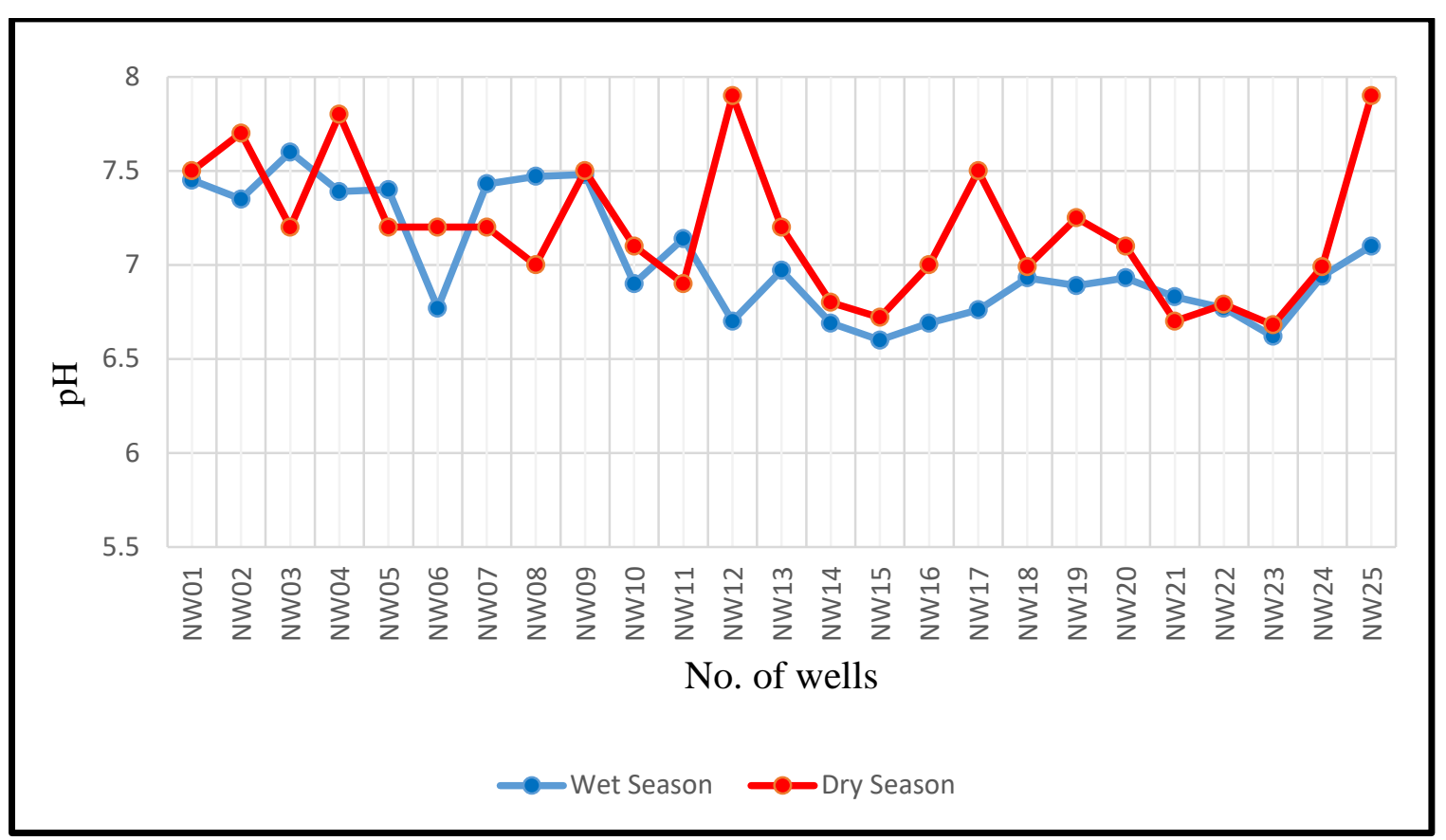

Figure 3: $\mathrm{pH}$ variation of wet and dry seasons

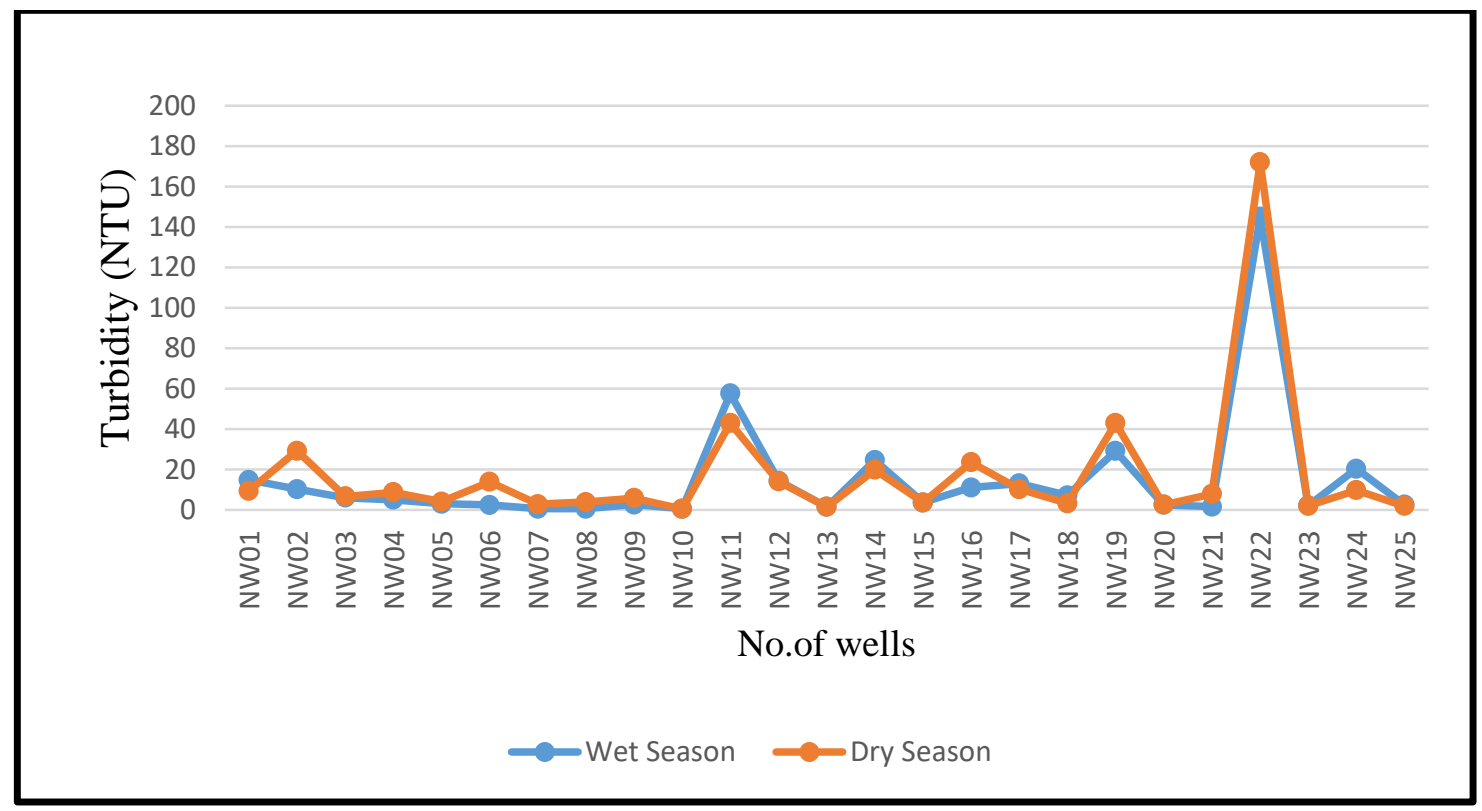

Figure 4: Turbidity variation of wet and dry seasons 


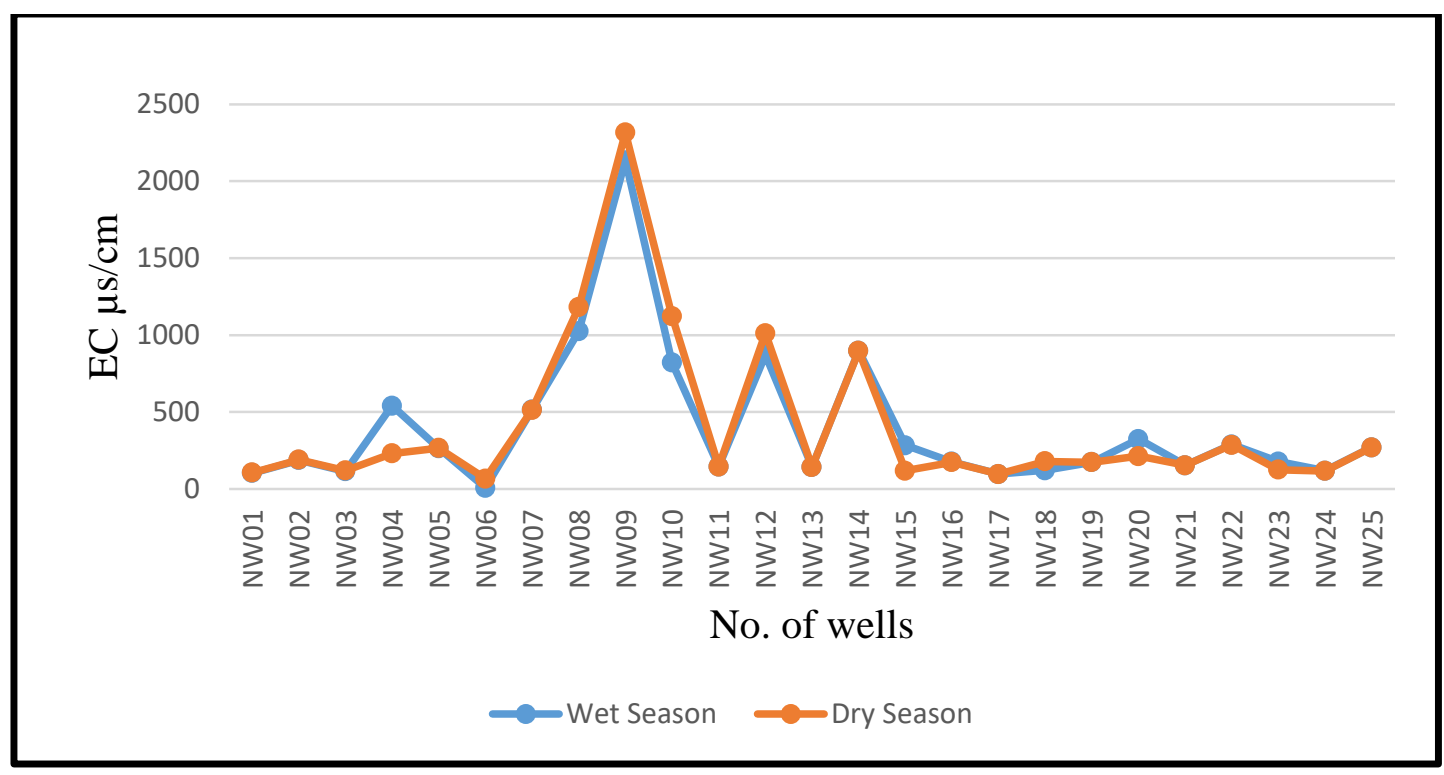

Figure 5: EC variation of wet and dry seasons

\subsection{Correlation of Spatial Distribution}

According to the methodology, 10 wells were selected much closed to the paddy land area and 15 wells were selected fairly far from the paddy land area to show the intensification of the agrochemical concentration.

NW05, NW06, NW07, NW09, NW10, NW12, NW15, NW20, NW22 and NW25 were selected much closed to the paddy land and downstream area. NW20 only has the $>0.1 \mathrm{mg} / \mathrm{l}$ of the Nitrate concentration rest have high level concentration both wet and dry seasons. Because, this well 20 feet deeper than others due to the fact that the chemical leaching rate is lower than the others. NW22 has higher turbid water because it is situated in downstream area. In wet season downstream area was affected more turbidity than dry season.

According to the data of water quality analysis, the more nearness of the wells have determine the concentration of the agrochemicals. Deepness also consider when the nearness. Likewise, the Phosphate concentration also determined the proximity of the location of the wells.

\subsection{Results}

According to the data analysis based on the report of water quality analysis, in Navithanveli DS Division the chemical concentration in both seasons have varied due to the application of the agrochemicals. The samples, collected in Dry season have clearly shown that the deviation of the all five parameter. Particularly, according to the water quality analysis report Nitrate and Phosphate concentrations are rapidly increasing. The agricultural practices are the main reason for increasing concentration because the wells much close to the paddy fields have higher concentration than others. Even the wells, very close to the paddy fields have lower concentration of Nitrate and Phosphate, the depth of the well is high, due to the fact that there is less likelihood to leach out the constituents to the deeper wells. 
The problems of this study are groundwater contamination by agro-chemicals' utilization, indiscriminate utilization of agro-chemicals and improper agro-chemicals' waste management. These problems are satisfied by the proper solutions. As an agricultural area Navithanveli DS Division is cultivated paddy in vast land. The agrochemical utilization has been caused the groundwater contamination according to the result of water quality data collected from Navithanveli DS Division in wet and dry seasons. In both wet and dry season, the variations of the agrochemicals are easily identifiable. The agrochemicals application has leached in to the groundwater according to the both seasons' water quality analysis report.

In Navithanveli DS Division farmers use the agrochemicals indiscriminate manner. They do not consider the environment but to the economic benefits. If any agrochemical product is introduced in the market they immediately use it for the betterment. Some farmers use the overdose for the pest and weed control considering rapid outcome.

Most of the farmers use many sort of agrochemicals such as from the tins, bags, bottles, polythene and other containers. These waste materials are thrown after the usage here and there without considering the environment. Due to the fact that many environmental problems are rising. The remaining chemicals in the waste material mix with water and soil. This leads to the agrochemicals leaching in to the groundwater.

\section{Conclusion}

The prime objective of this study 'identifying the groundwater contamination by the utilization of agro-chemicals in Navithanveli DS Division, attained by the water quality analysis from the sampling wells, collected in Navithanveli DS Division. The collected samples were subjected to the water quality analysis considering five parameters such as Nitrate, Phosphate, Electrical Conductivity, $\mathrm{pH}$, and Turbidity. All the parameters have varied in both seasons due to the agrochemicals application. Because during the period of the both seasons the paddy cultivation and harvesting was conducted. For the paddy cultivation numerous agrochemicals were applied. This is the reason for the groundwater contamination.

The Nitrate and Phosphate rich agrochemicals are increasingly applied in Navithanveli DS Division. To identify the chemical concentration the samples in both wet and dry seasons collected in two times. The Nitrate and Phosphate were mainly considered. According to the report of water quality analysis, one of the specific objectives 'finding out Nitrate and Phosphate concentration to identify the groundwater quality depletion by the chemical testing in the study area' was attained. In the result part the variation of Nitrate and Phosphate has been clearly shown in the figures. Rather than the concentration in the wet season, the concentration in dry season has increased in many wells particularly the wells, selected much closed to the paddy land. Even, rest wells have the low concentration, in future it may increase in rapidly due to the increasing and indiscriminate utilization of the agrochemicals.

Second specific objective 'identifying adverse agricultural practices in the study area' has been attained. In Navithaveli DS Division most people engage agriculture with many agricultural practices. At present, people use modern agricultural practices than traditional methods. Pest and weed control and enrichment of the crops are made using the modern agricultural practices. It is 
difficult to find out the manual weeding in agricultural land. The usage natural compost for the agriculture now has been decreased. For the agriculture, agrochemicals are applied indiscriminate manner. Excessive amount of agrochemicals are applied for the slight upnormal condition considering the economic benefits. People hope that the high amount of the agrochemicals usage definitely gives the high amount of yield. Therefore they use various sort of agrochemicals. Many farmers throw the agrochemicals waste materials in to the streams having utilized. The remaining of the wastes mix with water and cause a lot of problems. 25 people of the Navithanveli Ds Division were interviewed for the information in this regard.

Final specific objective 'to make awareness among agro-chemical users by inducing traditional agricultural practices and recommend favorable solutions to the groundwater oriented problems' has been attained after the analysis of the water quality and interviews. For the adverse agricultural practices traditional methods have been suggested as follow. Immediately inform to the water resource board to identify the chemical concentration in the wells situated in Navithanveli DS Division to reduce the future impacts, to cease the water extraction for the drinking purposes from the wells, identified high chemical concentration during this study, to identify the wells and take immediate measures to reduce the agrochemical concentration of the groundwater, providing awareness among farmers regarding the severity of the agrochemical concentrations and the importance of the groundwater and impact of the agrochemical concentration on the groundwater, inducing the traditional weed and pest controlling methods such as manual weeding and natural pesticides, utilizing organic fertilizer for the crop enrichment such as natural compost, controlling the tree planting closed to the wells, using separate water for the cleaning of the agrochemical application, instruments such as sprayers, pumps, and containers, disposing the waste materials in proper manner, following recommended dose for the application, to stop the excessive mixing and instruct the farmers in this regard.

\section{References}

[1] Adeoye, PA. Abubakar, Sani Kazaure \& Richard Adeolu, A. (2013). Effect of agrochemicals on groundwater quality: A Review. Scientia agriculture: Malaysia.

[2] Center for Watershed Sciences (2012). Nitrogen sources and loading to groundwater technical report 2. University of California: USA.

[3] Food and Agriculture Organization of the United Nations (2015). FAO Statistical Pocketbook: world food and agriculture. Rome.

[4] Kaleel MIM, (2015). The impacts of agro-well irrigation \& its impacts on Groundwater quality: A study based on Kuchchaveli area in Trincomalee district.

[5] Mikunthan T, \& De Silva CS, (2008). Vulnerability assessment for shallow aquifers using chemical quality of groundwater: A case study from Thirunelvely and Kondavil in Jaffna district: University of Jaffna.

[6] Ministry of Agriculture (2013). Performance report.

[7] Sinthuka V, (2013). Drinking water quality and the impact of tsunami on the groundwater quality in the coastal zones of the Jaffna peninsula, sri lanka. Asian University for Women. Society of Sri Lanka.

[8] Wijesekare RS, (2013). Excessive use of agrochemicals pollutes groundwater in many places. The Sunday Times. Retrieved from http://www.sundaytimes.lk/130922/news/excessive-use-ofagrochemicals-pollutes groundwater-in-many-places-63297.html

\footnotetext{
*Corresponding author.

E-mail address: knijamir@ gmail.com
} 